\title{
Hospice care compliance of nurses working at a hospice ward in Korea
}

\author{
Hyun Gu Lee ${ }^{1}$, Heeok Park ${ }^{2 *}$, Young Mi Chun ${ }^{3}$ \\ ${ }^{1}$ Keimyung University, Dongsan Hospital, Daegu, South Korea \\ ${ }^{2}$ College of Nursing, Keimyung University, Daegu, South Korea \\ ${ }^{3}$ College of Nursing, Taegu Science University, Daegu, South Korea \\ Email: $\underline{\text { hopark@kmu.ac.kr }}$
}

Received 18 November 2013; revised 25 December 2013; accepted 20 January 2014

Copyright (C) 2014 Hyun Gu Lee et al. This is an open access article distributed under the Creative Commons Attribution License, which permits unrestricted use, distribution, and reproduction in any medium, provided the original work is properly cited. In accordance of the Creative Commons Attribution License all Copyrights (C) 2014 are reserved for SCIRP and the owner of the intellectual property Hyun Gu Lee et al. All Copyright (C) 2014 are guarded by law and by SCIRP as a guardian.

\section{ABSTRACT}

Purpose: The purpose of this study was to investigate the hospice care compliance of nurses working at a hospice ward and provide meaningful data to improve the hospice care compliances. Methods: Participants included 104 nurses working at the hospice ward of the hospital located at $P$ and $D$ cities. Data was collected from February to March 2012. The level of hospice care compliance was measured using Bae (2000)'s questionnaires. Data were analyzed with descriptive statistics, t-test, one-way ANOVA and Scheffè test using SPSS/WIN 18.0 program. Results: The level of hospice care compliance in hospice nurses working at a hospice ward was high (3.25 out of 4). In hospice care compliance, the physical area was highest, followed by the emotional, spiritual, and social areas. Hospice care compliance was significantly different according to age, marital status, education, religion, importance of religion, job position, job satisfaction and life satisfaction. Hospice care compliance was also significantly different according to the nurses' experience of death, having license or certification related to hospice care and experiences related to clients' death. Conclusions: The findings of this study showed that the level of hospice care compliance was high and the hospice care compliance in South Korea was primarily focused on physical care. Considering that spiritual needs are important needs in hospice clients, hospice nurses need to focus on those aspects more. To improve the quality of hospice care compliance in the hospice nurses, programs to increase hospice nurses' job and life satisfaction are needed.

*Corresponding author.

\section{KEYWORDS}

Hospice Care; Compliance; Nurses

\section{INTRODUCTION}

Hospice palliative care is to relieve suffering and improve the quality of living and dying. Hospice palliative care strives to help patients and families: "1) address physical, psychological, social, spiritual and practical issues, and their associated expectations, needs, hopes and fears; 2) prepare for and manage self-determined life closure and the dying process; and 3) cope with loss and grief during the illness and bereavement" [1]. In the past, hospice care including end of life care was offered by families or relatives at clients' homes in South Korea. However, the most hospice care is currently provided at hospitals and the current attitude to hospice care at hospitals was changed because of the changes in the family composition in South Korea and the development of modern medical science [2].

In 1995 , end of life care was provided to $22.8 \%$ of dying clients in hospitals in South Korea, but the number has been increased to 59.9\% in 2006 [3]. Because of the increase in the need for end of life care in hospitals, nurses working at hospitals have more chance to care for dying clients and their roles are more important than before. To meet the diverse needs of dying clients, nurses need clinical competence and experience to care for dying clients physically, psychosocially, and spiritually but also improve quality of life in clients' families [4]. Nurses also need to support dying clients' opinions and respect their dignities [5].

Hospice care is offered by a multi-disciplinary team approach by physicians, nurses, social workers, priests 
and so on and nurses among them offer direct cares to clients for 24 hours as primary caregivers in South Korea. Hospice nurses also assess clients' health conditions, offer holistic cares, and provide continuous nursing cares [6-8]. For hospice care, there are four types of hospice care including hospital, scattered, home, and facility types in South Korea. The hospital type as the most common type of hospice care in Korea offers hospice care at an independent hospice ward of the hospital. One of the advantages in the hospital type is providing systemized hospice care with health professionals in the independent ward [9]. Since 2011 June, nurses working at a hospice ward are required to have a certified RN license and complete the Standard Curriculum of Hospice and Palliative Care Education with a total of 60 hours including 46 hours of theory and 14 hours of practice for nurses to improve quality of hospice care [10].

In the hospice care, nurses' important roles are to control pain and increase quality of life for hospice patients and to help bereavement management after death [4]. Although nurses are eager to provide appropriate end of life care, they have difficulty in doing so because of a shortage of time, lack of knowledge, communication problems, nurse' stress factors, and patients and families unmet care needs [11-13]. Unless nurses understand the values for dying clients and the important nursing roles, they are anxious or stressed $[12,14]$. Nurses who are married, older, and have more education, higher positions, and more clinical experience and end of life experience generally provide a higher level of hospice care [15-18].

Many studies regarding the hospice care were reported in South Korea and the studies included patients' needs about hospice care, the effects of hospice care on health problems, hospice nurses' stress and burden, end of life care experiences, ethical/politic issues and so on [19-23]. Many studies regarding the hospice care were conducted, but few studies were conducted to investigate the level or degree of hospice care and the studies were focused on home-visit nurses and general nurses working at ICU or cancer center not hospice ward $[23,24]$.

Because the hospice ward is the most common place to provide hospice care in the hospital and all nurses working at the hospice ward offer hospice care for patients, investigating the level of hospice care compliance of nurses working at the hospice ward is required. Thus, there is a need to investigate the level of hospice care compliance for nurses working at the hospice ward. The purpose of this study is to investigate the hospice care compliance of nurses working at the hospice ward and give meaningful suggestions to improve nurses' hospice care compliance and increase patients' quality of life. The specific purposes of this study are as follows:

1) To investigate the levels of hospice care compliance in nurses working at hospice ward.
2) To investigate the levels of hospice care compliance by the nurses' characteristics.

\section{METHOD}

\subsection{Design}

The study is a descriptive study to investigate the level of hospice care compliances of nurses working at a hospice ward.

\subsection{Sample Selection}

The PI contacted the nursing directors of 11 hospitals having a hospice ward in D-city, B-city, and K-province within three hours' drive from the PI's working place. A total of 104 nurses working at the 11 hospice wards completed the study. Based on the G*Power 3 Program analysis with moderate effect 0.25 , power 0.80 , and alpha value 0.05 , a minimum sample size was 104 . Allowing for a $10 \%$ of dropout rate, 116 subjects initially participated in the study, but 104 subjects' data were included for final data analysis because 12 subjects' data were not completed appropriately. The inclusion criteria of this study were as follows:

1) A nurse working in a hospice ward of the hospital;

2) A full-time regular nurse;

3) A nurse who understands the purpose and process of this study and agrees to participate in this study.

\subsection{Procedure}

The data collection was conducted from February to March 2012. The PI had visited the directors of nursing in 11 hospitals at D-city, B-city, and K-province to introduce this study and presented the purpose and meaning of this study to the directors of nursing, head nurses, and nurses. When the nurses understood the purpose of this study and agreed to participate, the PI obtained a formal consent from each of the nurses. After the consent was obtained, while the hospice nurses at D-city completed the questionnaires and the PI picked them up by herself, the nurses in the other cities answered the questionnaires and sent them back to the PI by mail because of their hospital conditions.

\subsection{Instruments}

1) Hospice care compliance

The level of hospice care compliance was measured using Bae (2001)'s questionnaire [25]. The questionnaire includes 49 questions with 4 areas (physical area with 11 questions, emotional 15, spiritual 14, and social 9). A Likert scale from "never carry out" 1 point to "always fulfill" 4 points was used, ranging from 1 to 4 possible points. A higher score in the questionnaire means higher levels of hospice nursing compliance. The Cronbach's 
alpha value of the questionnaire was initially 0.97 (physical area 0.89, emotional 0.93, spiritual 0.94, and social 0.93). In this study, the Cronbach's alpha value was 0.96 (physical area 0.79, emotional, 0.90, spiritual 0.92, and social 0.83).

\subsection{Ethical Approval}

The study was approved by K university D hospital IRB committee members (No. 12-18) and the data collection was started after the approval. The PI had provided sufficient explanations to the all participants regarding the purpose of this study and the contents. They were allowed that they could withdraw from the study whenever they want if they did not want to continue the participation. The personal information of the participants was kept confidentially in the PI's office room.

\subsection{Analysis}

Data analysis was conducted using SPSS/WIN 18.0 Program (SPSS, Inc., an IBM Company, Chicago, Illinois, USA). Descriptive statistics were used to describe subjects' characteristics and levels of hospice care compliance. T-test, One-way ANOVA, and Scheffe test were used to answer the levels of hospice care compliance by the subjects' characteristics.

\section{RESULTS}

\subsection{Subjects' Characteristics}

The findings of sample characteristics are presented in Table 1. Most participants were female (99\%), unmarried (64.4\%), diploma graduated (48.1\%), and Christian (40.4\%). Most participants were religious for more than 15years (29.8\%), thought that religion is important (66.4\%), had income more than 2,000,000 won/month (65.4\%), working experiences at general hospitals (63.5\%), clinical experiences less than 3 years (39.4\%), and working experiences in a hospice ward less than 3 years (62.5\%). Most participants were staff nurses (84.6\%), almost half of them were satisfied with the job (49.1\%), and satisfied with life (48.1\%). Regarding education related to hospice care, most participants had education about the topic of dying (81.7\%), had no license or certification of hospice care (58.7\%), and had certificates of hospice standard education (28.8\%). Most participants had experience of more than 20 cases of patients’ dying (66.3\%).

\subsection{Hospice Care Compliance}

The levels of hospice care compliance in subjects are presented in Table 2. The mean level of hospice care compliance was 3.25 out of 4 . The mean of nursing care compliance in the physical area was the highest (3.37) followed by the emotional area (3.35), spiritual area (3.13), and social area (3.09).

In the physical area of the nursing care compliance, "Check a client's BP, PR, RR, BT exactly" was the highest (3.80) following "Encourage a client to express his/her discomfort under the pain, document change of pain, medication status, and medication intervals after administrating, and observe the level of pain” (3.69), "Observe a client's symptoms frequently and notify to Dr if needed” (3.67), and “Change a client's position regularly and apply mattress to prevent bed sore” (3.59). The lowest part of the nursing hospice compliance in the physical area was "Help with high calorie, vitamin and protein intake” (2.86) following "Clean a client's discharge and help client going to the bathroom” (3.17), and "Change a client's clothes and sheet frequently when he/she is sweating” (3.18).

In the emotional area of the nursing care compliance, the highest items were "Genuine attitude to a client and his/her families" (3.66) and "Respect a client's privacy” (3.61). On the other hand, "Consider families not to be exhausted" (3.09) and "Talk to a client about his/her health status frankly" (3.10) were the lowest in that area.

In the spiritual area of the nursing care compliance, “Respect a client's beliefs, values, and existence” was the highest (3.35) following "Encourage a client's positive thinking and hope” (3.32), "Help a client understand the current status and keep his/her peace of mind” (3.28), and "Do not force a client's spiritual problems and respect his/her thinking as it is” (3.28). The lowest items were "Pray with a client and read/provide a religious book" (2.52) following "Help a client to participate in religious observances and keep a quiet environment" (3.03), “Consult a client's spiritual leader" (3.04), and "Use myself as a therapeutic tool” (3.06).

The level of social area in the nursing care compliance was low compared to other areas and the highest level on that area (educate families to be ready for a client's dying) was 3.49. The lowest item of the social area included "Offer a chance to meet other families who had lost their families" (2.83), "Offer a room to talk about client's will or legacy when needed” (2.93), "Counsel about social support to help families" (3.04), and "Request bereavement care to relieve families' grief after the client's dying” (3.05).

\subsection{Hospice Care Compliance According to the Subjects' Characteristics}

The hospice care compliance according to the subjects' characteristics is presented in Table 3 . There were significant differences in age $(F=4.17, p=0.008)$, marriage $(\mathrm{t}=-2.17, \mathrm{p}=0.032)$, education $(\mathrm{F}=4.88, \mathrm{p}=$ 
Table 1. Subject's characteristics. $(\mathrm{N}=104)$.

\begin{tabular}{|c|c|c|c|}
\hline Characteristics & Category & $\mathrm{N}$ & $\%$ \\
\hline \multirow{2}{*}{ Gender } & Male & 1 & 1.0 \\
\hline & Female & 103 & 99.0 \\
\hline \multirow{4}{*}{ Age (years) } & Less than 25 & 23 & 22.1 \\
\hline & $25-30$ & 45 & 43.3 \\
\hline & $31-35$ & 15 & 14.4 \\
\hline & More than 35 & 21 & 20.2 \\
\hline \multirow{3}{*}{ Marriage } & Not married & 67 & 64.4 \\
\hline & Married & 37 & 35.6 \\
\hline & Diploma & 50 & 48.1 \\
\hline \multirow[t]{2}{*}{ Education } & University & 37 & 35.6 \\
\hline & Graduate & 17 & 16.3 \\
\hline \multirow{4}{*}{ Religion } & Christian & 42 & 40.4 \\
\hline & Catholic & 22 & 21.2 \\
\hline & Buddhist & 10 & 9.6 \\
\hline & None & 30 & 28.8 \\
\hline \multirow{5}{*}{ Period of religion (years) ${ }^{*}$} & Less than 3 & 11 & 10.6 \\
\hline & $3-6$ & 12 & 11.5 \\
\hline & $7-11$ & 11 & 10.6 \\
\hline & $11-15$ & 9 & 8.7 \\
\hline & More than 15 & 31 & 29.8 \\
\hline \multirow{4}{*}{ Importance of religion } & Very important & 24 & 23.1 \\
\hline & Slightly important & 45 & 43.3 \\
\hline & Few important & 25 & 24.0 \\
\hline & Never important & 10 & 9.6 \\
\hline \multirow{3}{*}{ Income (10,000 won/month) } & $100-199$ & 36 & 34.6 \\
\hline & $200-299$ & 45 & 43.3 \\
\hline & More than 300 & 23 & 22.1 \\
\hline \multirow{2}{*}{ Working place } & University hospital & 38 & 36.5 \\
\hline & General hospital & 66 & 63.5 \\
\hline \multirow{4}{*}{ Clinical experience (years) } & Less than 3 & 41 & 39.4 \\
\hline & $4-6$ & 22 & 21.2 \\
\hline & $7-9$ & 10 & 9.6 \\
\hline & More than 10 & 31 & 29.8 \\
\hline \multirow{3}{*}{ Position } & Staff nurse & 88 & 84.6 \\
\hline & Charge nurse & 9 & 8.7 \\
\hline & Head nurse & 7 & 6.7 \\
\hline \multirow{4}{*}{ Job satisfaction } & Very satisfied & 2 & 1.9 \\
\hline & Slightly satisfied & 47 & 45.2 \\
\hline & Few satisfied & 51 & 49.1 \\
\hline & Never satisfied & 4 & 3.8 \\
\hline \multirow{4}{*}{ Life satisfaction } & Very satisfied & 4 & 3.8 \\
\hline & Slightly satisfied & 47 & 45.2 \\
\hline & Few satisfied & 50 & 48.1 \\
\hline & Never satisfied & 3 & 2.9 \\
\hline \multirow{4}{*}{$\begin{array}{l}\text { Working experience at a } \\
\text { hospice ward (years) }\end{array}$} & Less than 3 & 65 & 62.5 \\
\hline & $3-4$ & 25 & 24.0 \\
\hline & $5-8$ & 9 & 8.7 \\
\hline & More than 9 & 5 & 4.8 \\
\hline \multirow{2}{*}{ Education regarding dying } & Yes & 85 & 81.7 \\
\hline & No & 19 & 18.3 \\
\hline \multirow{2}{*}{$\begin{array}{l}\text { Having license or certification } \\
\text { regarding hospice care }\end{array}$} & Yes & 43 & 41.3 \\
\hline & No & 61 & 58.7 \\
\hline & Hospice nurse practitioner and certificate & 6 & 5.8 \\
\hline Types of license or certification & Certificate of hospice standard education & 30 & 28.8 \\
\hline gained regarding hospice care ${ }^{*, \dagger}$ & Certificate of hospice leadership course & 3 & 2.9 \\
\hline & Other & 7 & 6.7 \\
\hline & Less than 5 & 5 & 4.8 \\
\hline & $6-10$ & 6 & 5.8 \\
\hline Experiences on patient's death & $11-15$ & 14 & 13.5 \\
\hline & $16-20$ & 10 & 9.6 \\
\hline & More than 21 & 69 & 66.3 \\
\hline
\end{tabular}

*Included missing value; ${ }^{\dagger}$ Multiple responses. 
Table 2. Hospice care compliance of nurses working at hospice ward. ( $\mathrm{N}=104)$.

\begin{tabular}{|c|c|c|}
\hline Category & Items & $\mathrm{M} \pm \mathrm{SD}$ \\
\hline & Check a client's BP, PR, RR, BT exactly. & $3.80 \pm 0.40$ \\
\hline & $\begin{array}{l}\text { Encourage a client to express his/her discomfort under the pain, document change of pain, medication status, } \\
\text { and medication intervals after administrating, and observe the level of pain. }\end{array}$ & $3.69 \pm 0.46$ \\
\hline & Observe a client's symptoms frequently and notify to Dr if needed. & $3.67 \pm 0.49$ \\
\hline & Change a client's position regularly and apply mattress to prevent bed sore. & $3.59 \pm 0.51$ \\
\hline & Help a client's movement when his/her movement is limited by powerlessness or paralysis. & $3.37 \pm 0.52$ \\
\hline \multirow[t]{14}{*}{ Physical } & Provide skin care to prevent skin damage by incontinence. & $3.29 \pm 0.60$ \\
\hline & Control room temperature and ventilation and arrange the room environment. & $3.26 \pm 0.52$ \\
\hline & $\begin{array}{l}\text { Pay attention to managing special tools (L-tube, F-cath, PTBD etc) and represent a client's opinions when } \\
\text { he/she wants to remove them. }\end{array}$ & $3.23 \pm 0.56$ \\
\hline & Change a client's clothes and sheet frequently when he/she is sweating. & $3.18 \pm 0.48$ \\
\hline & Clean a client's discharge and help going to the bathroom. & $3.17 \pm 0.68$ \\
\hline & Help with high calorie, high vitamin, and high protein intake. & $2.86 \pm 0.67$ \\
\hline & Subtotal & $3.37 \pm 0.31$ \\
\hline & Genuine attitude to a client and his/her families. & $3.66 \pm 0.48$ \\
\hline & Respect client’s privacy. & $3.61 \pm 0.49$ \\
\hline & Keep amicable relationship with a medical team. & $3.47 \pm 0.56$ \\
\hline & Treat a client with smile and kindness. & $3.41 \pm 0.55$ \\
\hline & Listen to a client's appeals courteously. & $3.57 \pm 0.50$ \\
\hline & Discuss sedatives or antidepressants to relieve a client's anxiety with a doctor. & $3.40 \pm 0.57$ \\
\hline & Explain the procedures of nursing treatments to a client for his/her understanding while nursing treatments. & $3.40 \pm 0.53$ \\
\hline \multirow[t]{9}{*}{ Emotional } & Reflect a client's opinions in the medical and nursing treatments. & $3.38 \pm 0.55$ \\
\hline & Plan the meeting time with doctors and clients if needed. & $3.38 \pm 0.53$ \\
\hline & Delay the conversation time to later when a client refuses the time. & $3.30 \pm 0.50$ \\
\hline & $\begin{array}{l}\text { Talk with a client frequently to express his/her feelings and help his/her understanding } \\
\text { (fear, anxiety, loneliness, concerns about dying, guilty etc.). }\end{array}$ & $3.18 \pm 0.54$ \\
\hline & $\begin{array}{l}\text { Understand a client's physical and emotional dependence, encourage his/her partial self-care, } \\
\text { and improve his/her self-esteem. }\end{array}$ & $3.18 \pm 0.54$ \\
\hline & Encourage a client to select his/her own life style, medical treatments, and nursing treatments by himself/herself. & $3.11 \pm 0.46$ \\
\hline & Talk to a client about his/her health status frankly. & $3.10 \pm 0.49$ \\
\hline & Consider families not to be exhausted. & $3.09 \pm 0.56$ \\
\hline & Subtotal & $3.35 \pm 0.34$ \\
\hline
\end{tabular}




\section{Continued}

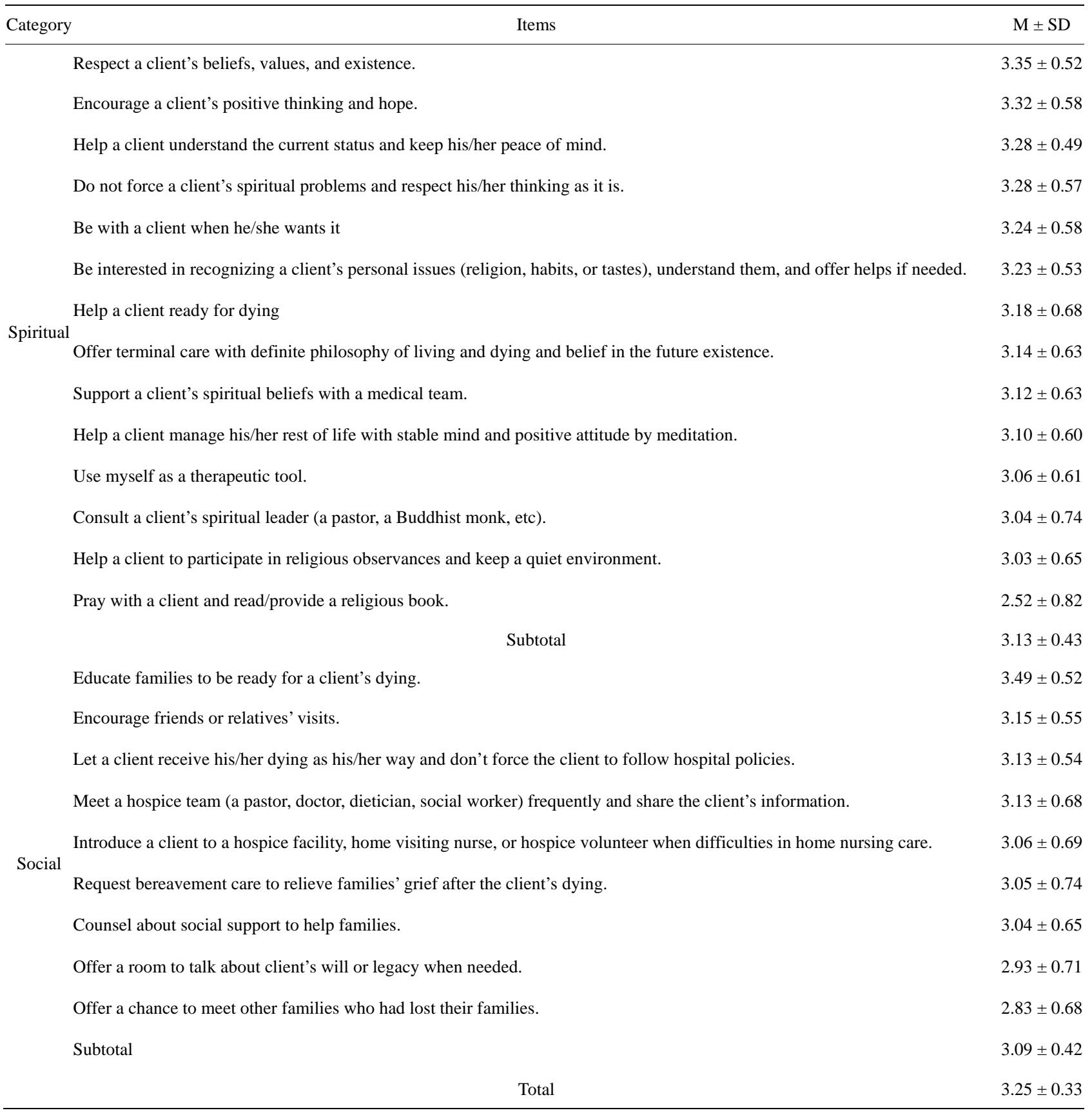

0.009), religion ( $\mathrm{F}=6.29, \mathrm{p}=0.001)$, importance of religion $(\mathrm{F}=5.98, \mathrm{p}=0.001)$, clinical experiences $(\mathrm{F}=3.40$, $\mathrm{p}=0.021)$, job satisfaction $(\mathrm{F}=4.97, \mathrm{p}=0.003)$, life satisfaction $(\mathrm{F}=8.57, \mathrm{p}<0.001)$, education experiences regarding dying $(\mathrm{t}=2.09, \mathrm{p}=0.039)$, having license or certification about hospice care $(\mathrm{t}=2.57, \mathrm{p}=0.011)$, and experiences on patients' death $(\mathrm{F}=3.90, \mathrm{p}=0.006)$. Hospice nurses who are over age 35 showed better hospice care compliance than those aged 25 - 30 and married hospice nurses showed better hospice care compliance than non-married nurses. Highly educated (grad- uate college) nurses showed high levels of hospice care compliance compared to others (college or diploma graduated), and nurses who have religion did more compared to non-believers. Nurses with more than 10 years' experience had higher levels of hospice care compliance than nurses with less than 3 years. Nurses who are satisfied with job and life reported high levels of hospice care compliance. Nurses who have education experiences regarding clients' dying and have license or certification about hospice care showed higher levels of hospice care compliance than others. 
Table 3. Differences in hospice nursing compliance according to subjects' characteristics $(\mathrm{N}=104)$.

\begin{tabular}{|c|c|c|c|c|c|}
\hline Characteristics & Category & $\mathrm{M} \pm \mathrm{SD}$ & t or F & $p$ & Scheffè \\
\hline \multirow{3}{*}{ Gender } & Male & $2.95 \pm 0.00$ & \multirow{3}{*}{-0.91} & \multirow{3}{*}{0.362} & \\
\hline & Female & $3.26 \pm 0.33$ & & & \\
\hline & Less than 25 & $3.22 \pm 0.40$ & & & \\
\hline \multirow{3}{*}{ Age (years) } & $25-30$ & $3.17 \pm 0.30$ & \multirow{3}{*}{4.17} & \multirow{3}{*}{0.008} & \multirow{3}{*}{$\mathrm{a}<\mathrm{b}$} \\
\hline & $31-35$ & $3.25 \pm 0.23$ & & & \\
\hline & More than 35 & $3.46 \pm 0.29$ & & & \\
\hline \multirow{3}{*}{ Marriage } & Not married & $3.20 \pm 0.34$ & \multirow{3}{*}{-2.17} & \multirow{3}{*}{0.032} & \\
\hline & Married & $3.34 \pm 0.29$ & & & \\
\hline & Diploma & $3.23 \pm 0.32$ & & & \\
\hline \multirow[t]{3}{*}{ Education } & University & $3.18 \pm 0.33$ & \multirow[t]{3}{*}{4.88} & \multirow[t]{3}{*}{0.009} & \multirow[t]{3}{*}{$\mathrm{a}, \mathrm{b}<\mathrm{c}$} \\
\hline & Graduate & $3.46 \pm 0.27$ & & & \\
\hline & Christian & $3.33 \pm 0.37$ & & & \\
\hline \multirow{4}{*}{ Religion } & Catholic & $3.30 \pm 0.26$ & 6.29 & 0.001 & a. b, $c>d$ \\
\hline & Buddhist & $3.40 \pm 0.25$ & 6.29 & 0.001 & $\mathrm{a}, \mathrm{D}, \mathrm{c}>\mathrm{C}$ \\
\hline & None & $3.15 \pm 0.47$ & & & \\
\hline & Less than 3 & $3.26 \pm 0.33$ & & & \\
\hline & $3-6$ & $3.18 \pm 0.31$ & & & \\
\hline Period of religion (years) ${ }^{*}$ & $7-11$ & $3.36 \pm 0.26$ & 1.10 & 0.365 & \\
\hline & $11-15$ & $3.39 \pm 0.34$ & & & \\
\hline & More than 15 & $3.39 \pm 0.35$ & & & \\
\hline & Very important & $3.41 \pm 0.36$ & & & \\
\hline Imnortance of religion & Slightly important & $3.29 \pm 0.31$ & 5.98 & 0.001 & $\mathrm{a} \mathrm{h}>\mathrm{c}$ \\
\hline importance or religion & Few important & $3.07 \pm 0.27$ & 3.98 & 0.001 & $\mathrm{a}, \mathrm{D}>\mathrm{C}$ \\
\hline & Never important & $3.11 \pm 0.26$ & & & \\
\hline & $100-199$ & $3.22 \pm 0.36$ & & & \\
\hline Income (10,000 won/month) & $200-299$ & $3.20 \pm 0.30$ & 2.91 & 0.059 & \\
\hline & More than 300 & $3.39 \pm 0.29$ & & & \\
\hline Workino place & University hospital & $3.18 \pm 0.32$ & & & \\
\hline Workıng place & General hospital & $3.29 \pm 0.33$ & -1.563 & 0.121 & \\
\hline & Less than 3 & $3.16 \pm 0.34$ & & & \\
\hline & $4-6$ & $3.21 \pm 0.34$ & & & \\
\hline Clinical experience (years) & $7-9$ & $3.27 \pm 0.38$ & 3.40 & 0.021 & $\mathrm{a}<\mathrm{b}$ \\
\hline & More than 10 & $3.39 \pm 0.29$ & & & \\
\hline & Staff nurse & $3.22 \pm 0.33$ & & & \\
\hline Position & Charge nurse & $3.34 \pm 0.22$ & 2.915 & 0.059 & \\
\hline & Head nurse & $3.51 \pm 0.31$ & & & \\
\hline & Very satisfied & $3.62 \pm 0.06$ & & & \\
\hline Job satisfaction & Slightly satisfied & $3.35 \pm 0.30$ & 4.97 & 0.003 & $a>b$ \\
\hline Job satısfaction & Few satisfied & $3.13 \pm 0.31$ & 4.97 & 0.003 & $\mathrm{a}>\mathrm{b}$ \\
\hline & Never satisfied & $3.37 \pm 0.57$ & & & \\
\hline & Very satisfied & $3.60 \pm 0.12$ & & & \\
\hline & Slightly satisfied & $3.35 \pm 0.30$ & & & \\
\hline Life satisfaction & Few satisfied & $3.11 \pm 0.30$ & 8.57 & $<0.001$ & $\mathrm{a}, \mathrm{b}>\mathrm{c}$ \\
\hline & Never satisfied & $3.56 \pm 0.42$ & & & \\
\hline & Less than 3 & $3.21 \pm 0.33$ & & & \\
\hline Working exnerience at a Hosnice ward (years) & $3-4$ & $3.28 \pm 0.31$ & 099 & 0398 & \\
\hline working experience at a Hospice ward (years) & $5-8$ & $3.36 \pm 0.36$ & 0.99 & 0.398 & \\
\hline & More than 9 & $3.38 \pm 0.31$ & & & \\
\hline Education regarding dying & Yes & $3.28 \pm 0.33$ & 2.09 & 0.039 & \\
\hline Educatıon regardıng dyıng & No & $3.11 \pm 0.32$ & 2.09 & 0.039 & \\
\hline Having license or certification & Yes & $3.35 \pm 0.33$ & & & \\
\hline regarding hospice care & No & $3.18 \pm 0.31$ & $2.5 \%$ & 0.011 & \\
\hline & Hospice nurse practitioner and certificate & $3.57 \pm 0.29$ & & & \\
\hline Types of license or certification & Certificate of Hospice standard education & $3.29 \pm 0.32$ & & & \\
\hline gained regarding hospice care ${ }^{*, \dagger}$ & Certificate of leadership course & $3.46 \pm 0.33$ & 1.38 & 0.263 & \\
\hline & Other & $3.34 \pm 0.45$ & & & \\
\hline & Less than 5 & $3.00 \pm 0.37$ & & & \\
\hline & $6-10$ & $3.30 \pm 0.37$ & & & \\
\hline Experiences on patient's death & $11-15$ & $3.01 \pm 0.31$ & 3.90 & 0.006 & $\mathrm{a}<\mathrm{b}$ \\
\hline & $16-20$ & $3.18 \pm 0.32$ & & & \\
\hline & More than 21 & $3.32 \pm 0.30$ & & & \\
\hline
\end{tabular}




\section{DISCUSSION}

The purpose of this study was to investigate the hospice care compliance of nurses working at a hospice ward and to provide basic data of improving the hospice care compliance. In this study, the level of hospice care compliance of the nurses working at hospice ward was high, 3.25 out of 4 , compared to other clinical nurses working at general wards (2.81 out of 4 ) or ICU nurses (2.76 out of 4) $[16,25]$. The reasons for the high level of hospice care compliance in nurses working at hospice ward compared to the other nurses are thought to be that the ratio of nurses and hospice clients is higher than others, so that the nurses working at hospice ward could offer high quality of care.

In the sub-category of the hospice care compliance, the level of physical area in the hospice care compliance was the highest. Because there was no study reported investigating the hospice care compliance using the same instrument, so that it was difficult to compare the findings of the study with others, but the finding of this study was consistent with the finding of No's study that the physical area in the hospice care compliance was the highest [17]. In this study, the level of spiritual area was low and the finding was consistent with other studies $[15,16,18]$. Nurses working at hospice ward in this study focused on physical care more than the spiritual care even though hospice clients still have higher levels of spiritual needs at the end of life compare to other moments and the spiritual care is one of the most important roles in nurses working at hospice ward [26]. Hospice nurses are good at pain management and symptom management but they have difficulties in the area of the spiritual care and psychosocial care in the hospice care [4]. Thus, developing a culturally sensitive and objective tool first to assess the spiritual needs of hospice clients and trying to meet client's spiritual needs specifically are needed.

In the physical area of the hospice care compliance, nurses at hospice ward perform 'vital sign check' and 'pain management' frequently, but level of 'clean clients' discharge' and 'encouraging nutritional intake' was low. On the other hand, in Kim's study [21], nurses working at ICU perform 'removing client's discharge' frequently. The inconsistent finding is because clients' family members at hospice ward rather than nurses usually 'remove clients' discharges' and nurses at ICU do rather than the families. In the hospice ward, clients usually stay with their families so that nurses are inclined to shift cleaning clients' discharge on families. For the better quality of care, nurses need to involve direct care such as cleansing clients' discharge.

In the emotional area, the level of respecting client's privacy with sincere attitude in hospice nurses was high, but the communication level such as talking to a client about his/her health status or talking to express his/her feelings was low. In Anthony and Scarcelli's study, one of the important cost-effective approaches to corporate compliance for hospice and home health providers is communication. Communicating compliance standards, policies, and procedures among organization, employees, agents, and clients is emphasized in the study. Based on the findings, nurses working at hospice ward need to have more time to communicate clients and families but also understand clients' feelings and families' exhaustions.

In the spiritual area, the level of respecting hospice clients' beliefs or values and encouraging a client's positive thinking was high, but the level of helping clients' religious activities such as consulting a client's spiritual leader, helping a client to participate in religious observances, and praying with a client was low. In Wang and Chen's study [28], terminal cancer patients in an ICU exhibited spiritual disturbance and the spiritual disturbance including the fear of death was overcame by encouraging a joint of nurses, hospice care team, and religious chaplain. In Korea, spiritual care is currently encouraged with hospice care, but in this study helping the clients to participate in religious activities was not active. To increase the spirituality of hospice clients, nurses need to design the regular time to pray with hospice clients and help them to participate in the religious activities with the spiritual leaders.

In the social area, the level of educating families to be ready for a client's dying or encouraging friends or relatives' visits was high, but the level of offering a room to talk about clients' will or legacy when needed or offering a chance to meet other families who had lost their families was low. Many studies reported that talking about clients' living will and offering the bereavement program with hospice clients are important to increase patient access to hospice care $[29,30]$. In Korea, talking about clients' living will is not that culturally easy issue even with hospice clients, but offering a private room to talk about client's living will is needed. Anttonen, Nikkonen, and Tarja suggested that privacy, time spent together, being present at the time of death created a feeling of caring environment and more time for farewells after death is important for the quality of hospice care [31]. Based on the findings, being present with the client but also providing privacy is needed.

The current study reported that nurses who were highly educated (graduate college) showed the higher level of hospice care compliance than others (diploma or college) and the nurses who were believers showed the higher level of hospice care compliance than non-believers. The findings were consistent with the other studies which were conducted for ICU nurses or general nurses [15-17, 
32]. Based on the findings of this study, nurses working at hospice ward are encouraged to take more education programs related to hospice care and participate in the religious activities with hospice clients. In addition, nurses who have clinical experiences more than 10 years and have better job and life satisfaction showed high level of hospice care compliance compared to the others $[15,17]$. Thus, counseling and mentoring to improve nurses' job and life satisfaction at the hospice ward is suggested to increase the hospice care compliance.

The previous studies reported that hospice clients have more emotional needs than physical and spiritual needs [33-35]. In this study, nurses working at hospice ward showed high level of hospice care compliance in the physical area more than the other areas such as emotional, spiritual, and social area. Even though the hospice clients have more emotional needs, nurses working at hospice ward showed high level of hospice care compliance in the physical area. The findings show that the priority of hospice clients' needs differs from the priority of hospice care compliance in nurses. Thus, trials to assess hospice clients' needs and to plan hospice care according to the priority of the clients' needs are needed.

There are a couple of limitations in this study. This study was conducted at 11 hospitals having the hospice ward in a few cities so that the findings of this study are limited to generalize to the other cities. Hospice care compliance in this study was answered by the nurses working at hospice ward not hospice nurses licensed. Because the roles of hospice nurses licensed are important in the hospice ward, investigating the level of hospice care compliance for only hospice nurses licensed is needed. Also, there is a need to compare the level of hospice care compliance between the general nurses working at hospice ward and hospice nurses licensed. In this study, Bae's [25] questionnaires developed by Korean was used to measure hospice care compliance so that the findings of this study could not be compared with the international studies because the different instruments were used in the studies. For the further studies, by using the international instruments to measure hospice care compliance, comparing the level of hospice care compliance among countries is suggested.

\section{CONCLUSION}

The purpose of this study was to investigate the level of hospice care compliance in nurses working at hospice ward and provide meaningful data to improve the hospice care compliance. The level of the hospice care compliance in nurses working at hospice wards was high compared to the nurses working at general wards or ICU. The hospice care compliances of nurses working at hospice ward were high in physical area following the emotional, spiritual, and social areas. The hospice care com- pliances in nurses who are aged, married, highly educated, and having religion and high position were high compared to the others. In addition, nurses who are satisfied with their jobs and lives showed high level of hospice care compliance. Thus, to meet the hospice clients' emotional and spiritual needs, the education programs to remind the importance of emotional and spiritual care for hospice clients are required because the nurses are inclined to focus on the hospice clients' physical needs.

\section{REFERENCES}

[1] Canadian Hospice Palliative Care Association (2012) About us the Canadian hospice palliative care association. http://www.chpca.net/about-us.aspx

[2] Lee, H.J. (2003) A study on nurse's attitude toward death and hospice. The Journal of Research Institute for Hospice \& Palliative Care, 7, 87-104.

[3] Statistics Korea (2007) 2006 Mortality statistics. http://kostat.go.kr/portal/korea/kor nw/2/6/2/index.board ?bmode $=$ read \&bSeq $=\& a S e q=64502 \&$ pageNo=1\&rowNu

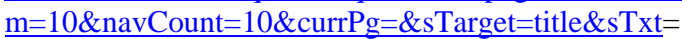

[4] Kim, B.H., Choe, S.O., Chung, B.Y., Yoo, Y.S., Kim, H.S., Kang, K.A., et al. (2010) Job analysis for role identification of general hospice palliative nurse. The Korean Journal of Hospice and Palliative Care, 13, 13-23.

[5] Gerry, E.M. (2011) Privacy and dignity in a hospice environment: The development of a clinical audit. International Journal of Palliative Nursing, 17, 92-98.

[6] McKenna, H., Keeney, S. and Nevin, L. (1999) Perceptions of GPs and DNs on the role of hospice home-care nurses. International Journal of Palliative Nursing, 5, 288295.

[7] Sullivan, K.A., McLaughlin, D. and Hasson, F. (2005) Exploring district nurses' experience of a hospice at home service. International Journal of Palliative Nursing, 11, 460-466.

[8] Wu, H.-L. and Volker, D.L. (2009) Living with death and dying: The experience of Taiwanese hospice nurses. Oncology Nursing Forum, 36, 578-584. http://dx.doi.org/10.1188/09.ONF.578-584

[9] Korea Hospice Association (2005) Hospice introduction. Korea Hospice Association Press, Seoul.

[10] Ministry of Health \& Welfare (2011) Cancer control act enforcement rules. http://www.law.go.kr/LSW/lsInfoP.do?lsiSeq=113804\#0 $\underline{000}$

[11] Lee, H.Y., Lee, Y.O., Choi, E.Y. and Park, Y.M. (2007) A comparison on stress and coping of bereavement care between nurses in the cancer unit and nurses in the general unit. Journal of Korean Oncology Nursing, 7, 26-35.

[12] Martens, M.L. (2009) A comparison of stress factors in home and inpatient hospice nurses. Journal of Hospice \& Palliative Nursing, 11, 144-153. http://dx.doi.org/10.1097/NJH.0b013e3181a1ac87

[13] Park, I.S. and Sung, E.O. (1991) A study of the attitudes of nurse and nursing students towards death and dying 
patients. Chungnam Medical Journal, 18, 677-694.

[14] Tunnah, K., Jones, A. and Johnstone, R. (2012) Stress in hospice at home nurses: A qualitative study of their experiences of their work and wellbeing. International Journal of Palliative Nursing, 18, 283-289.

[15] Ahn, S.N. (2004) A study of the correlation among the degree of nurse's suffering experience, death orientation, and terminal care performance. Unpublished MS Thesis, Catholic University of Daegu, Gyeongsangbuk-do.

[16] Kim, S.E. (2011) The relationship between intensive care unit nurses' death perception and terminal care performance. Unpublished MS Thesis, Ajou University, Gyeonggi-do.

[17] No, S.S. (2010) A study on death perception, terminal care attitude, and terminal care performance of clinical nurses caring for cancer patients. Unpublished MS Thesis, Sungkyunkwan University, Seoul.

[18] Shin, H. J. (2012) The influence of performance of terminal care on professionalism and good death awareness in clinical nurses. Unpublished Master's Thesis, Chungju University, Chungcheongbuk-do.

[19] Jeong, M.G. (2012) A study on the experiences of terminal care by nurses in the hospice-palliative care unit. Journal of Korean Association for Qualitative Research, 12, 50-65.

[20] Kang, K.-A. (2011) Development and effects of death preparation education for middle-aged adults. The Korean Journal of Hospice and Palliative Care, 14, 204-211.

[21] Kim, B.H. (2011) Current and future of hospice and palliative care in South Korea. The Korean Journal of Hospice and Palliative Care, 14, 191-196.

[22] Lee, Y.E. and Choi, E.J. (2011) Trends in research on hospice care in Korea. The Korean Journal of Hospice and Palliative Care, 13, 13-23.

[23] Seo, Y.-S. and Sung, K.-W. (2012) Influence of nurses' spirituality on hospice nursing intervention in long-term care facilities. Journal of Korean Gerontological Nursing, 14, 12-20.

[24] Yong, J.S., Ro, Y.J., Han, S.S. and Kim, M.J. (2002) A comparison between home care nursing intervention for hospice and general patients. The Journal of Research Institute for Hospice and Palliative Care, 6, 15-18.

[25] Bae, Y.R. (2001) The degree of clinical nurses' perception of hospice care and their performance and the degree of hospice patients' expectation and satisfaction. The Journal of Research Institute for Hospice \& Palliative Care, 5, 23-36.

[26] Reele, B.L. (1994) Effect of counseling on quality of life for individual with cancer and their families. Cancer Nursing, 17, 101-112.

http://dx.doi.org/10.1097/00002820-199404000-00004

[27] Anthony J. and Scarcelli, Jr. (2001) Cost-effective approaches to corporate compliance for hospice and home health providers. Home Health Care Management \& Practice, 13, 176-183. http://dx.doi.org/10.1177/108482230101300302

[28] Wang, C.-Y. and Chen, T.-F. (2012) The end-of-life intensive care experience of a terminal cancer patient combined with hospice care. Tzu Chi Nursing Journal, 11, 110-119.

[29] Lachman, V.D. (2011) Ethics, law, and policy: Nurse’s role in increasing patient access to hospice care. MEDSURG Nursing, 20, 200-2007.

[30] O’Connor, M., Abbott, J.-A., Payne, S. and Demmer, C. (2009) A comparison of bereavement services provided in hospice and palliative care settings in Australia, the UK and the USA. Progress in Palliative Care, 17, 69-74. http://dx.doi.org/10.1179/096992609X392240

[31] Anttonen, M.S., Nikkonen, M. and Kvist, T. (2011) The quality of hospice care assessed by family members of patients in a Finish Hospice: The pilot study to develop hospice care in Finland. Journal of Hospice \& Palliative Nursing, 13, 318-325. http://dx.doi.org/10.1097/NJH.0b013e31821fc52f

[32] Park, S.J. and Choi, S.H. (1996) A study on the degrees of death orientation and terminal care performance of nurses. The Korean Journal of Fundamentals of Nursing, 3, 285-297.

[33] Cho, K.M. (2006) Analysis of hospice care needs of patients with terminal lung cancer and their families. Unpublished MS Thesis, Yonsei University, Seoul.

[34] Jang, A.R. (2012) Hospice nursing demand of terminal cancer patient and family between general ward and hospice ward. Unpublished MS Thesis, Chonnam National University, Gwangju.

[35] Sohn, S.K. (2009) Needs of hospice care in families of the hospitalized terminal patients with cancer. Journal of Korean Oncology Nursing, 9, 1-6. 